Max-Planck-Institut für demografische Forschung

Max Planck Institute for Demographic Research

Konrad-Zuse-Strasse 1 - D-18057 Rostock · GERMANY

Tel +49 (0) 3812081 - 0; Fax +49 (0) 3812081 - 202;

http://www.demogr.mpg.de

MPIDR WORKING PAPER WP 2005-034

NOVEMBER 2005

\title{
Economic uncertainty and fertility postponement Evidence from German panel data
}

Michaela Kreyenfeld (kreyenfeld@ demogr.mpg.de)

This working paper has been approved for release by: Gerda Ruth Neyer (neyer@ demogr.mpg.de) Deputy Head of the Laboratory of Contemporary European Fertility and Family Dynamics.

(C) Copyright is held by the authors.

Working papers of the Max Planck Institute for Demographic Research receive only limited review. Views or opinions expressed in working papers are attributable to the authors and do not necessarily reflect those of the Institute. 


\title{
Economic Uncertainty and Fertility Postponement Evidence from German Panel Data
}

\author{
Michaela Kreyenfeld ${ }^{\star}$
}

\begin{abstract}
This paper investigates whether economic uncertainty induces a postponement of family formation. We use data from the German Socio-Economic Panel which provides longitudinal information of economic uncertainty and fertility for the period 1984 to 2004. We employ 'objective' measures of uncertainty (unemployment, fixed-term contract, low income) as well as 'subjective' measures (the feeling that the personal economic situation is insecure). Our results suggest that there is no clear indication that economic uncertainty generally leads to a postponement of parenthood. More highly educated women tend to postpone family formation when unemployed or when they feel insecure about their personal economic situation. However, women with low educational levels accommodate themselves quite readily with motherhood when subject to labor market insecurities.
\end{abstract}

Keywords: Economic uncertainty, fertility, Germany

* Author's correspondence address: Michaela Kreyenfeld, Max Planck Institute for Demographic Research, Konrad-Zuse Str. 1, 18057 Rostock. Phone: +49-381-2081-136 Email: kreyenfeld@demogr.mpg.de. 


\section{Introduction}

Over the last decades, most European countries have witnessed a dramatic shift of childbearing to older ages. This development is one of the most significant demographic changes that Western industrialized countries have been experiencing. The increase in the age at childbirth plays a significant role in the decline of annual fertility rates. It has also become evident that the delay in family formation is the prime cause of the recent fertility decline in Southern and Eastern Europe (Bongaarts 1999: 256; Sobotka 2004). Fertility delay has long-term consequences for completed fertility, given that a late age at first birth reduces the chances of having any further children (Marini and Hodson 1981; Morgan and Rindfuss 1999).

Women's education, employment and career orientation have been identified as chief parameters for the increase in the age at childbirth (Rindfuss et al. 1996; Martin 2000; Gustafsson 2001). In more recent publications, it has been stipulated that youth unemployment, term-limited working contracts and unstable employment situations are other factors that induce a postponement of childbearing (McDonald 2000: 10f.; De la Rica and Iza 2005; Adsera 2004; Blossfeld et al. 2005). Economic uncertainty is also regarded to be among the main driving forces behind the fertility postponement and the unprecedented decline in period fertility rates which occurred all over Eastern Europe after the demise of the communist systems (Eberstadt 1994; Witte and Wagner 1995; Adler 1997; Ranjan 1999; Kharkova and Andreev 2000). The delay in family formation

may thus reflect growing uncertainty about the economic future that individuals in contemporary societies face.

However, little empirical evidence exists on the relationship between economic uncertainty and fertility. On the macro level, sudden economic downswings have left their clear imprint on annual fertility rates. The Great Depression is an example, where a sudden increase in unemployment was followed by an erratic drop in birth rates (Kiser and Whelpton 1953). The fertility development in East Germany after unification is another example (Witte and Wagner 1995; Huinink and Kreyenfeld 2005). It is unclear, 
though, if historically exceptional situations of this kind can be generalized. On the micro-level, some studies have addressed the role of unemployment in fertility (Hoem 2000; Santow and Bracher 2001; Kravdal 2002; Vikat 2004; Kurz et al. 2005). Some other studies have investigated how fertility intentions are influenced by subjective indicators of economic uncertainties (Kohler and Kohler 2002; Speder and Vikat 2005). However, hardly any study exists that deals with the impact of subjective measures of economic uncertainty on fertility behavior. That there is little micro-level evidence for the uncertainty-fertility nexus can particularly be attributed to the strong demand on data quality. In order to study how an insecure economic situation affects subsequent childbearing, one requires longitudinal data on fertility, attitudes and employment. Such data is rarely available.

The aim of this paper is to investigate the role of economic uncertainties in first birth decisions in Germany using event history techniques. We use data from the German Socio-Economic Panel (SOEP) which provides longitudinal information on fertility, labor market characteristics and attitudes for the period 1984 to 2004. We employ 'objective' measures of uncertainty (unemployment, fixed-term contract, low income) as well as 'subjective' measures (the feeling that the personal economic situation is insecure). A major focus of our analysis is on how the effect of economic uncertainty differs by socioeconomic characteristics. Since the SOEP is one of the largest and longest panels in Europe, it provides sufficient sample size for such kind of analysis. The paper is structured as follows: In the following part, we develop our main research hypotheses. Section 3 reviews empirical studies which deal with the uncertainty and fertility nexus. Section 4 gives an overview on data and methods. Section 5 presents the empirical results. 


\section{Theoretical approaches to economic uncertainty and fertility}

\subsection{Classical fertility theories and the economic foundation of parenthood}

There is a long tradition in fertility research which is rooted in the idea that family formation requires a secure economic foundation. In his famous 'essay on population' from 1798, Malthus claimed that food supply and population growth were closely interrelated. Although Malthus believed that the chief mechanisms that balanced food supply and population growth were starvation, death and poverty, he nevertheless posited that economic hardship might induce people to delay marriage and fertility. The idea that family formation requires an adequate economic underpinning has also shaped social institutions. The 'western European marriage pattern' of high percentages of never married persons was directly linked to social norms which excluded unskilled laborers from the rights to get married (Hajnal 1965). When children were expected to only occur within marriage, such regulations were efficient means to limit fertility of those unable to support a family by their own means.

The idea that economic conditions and fertility are related was severely challenged by the demographic developments widely known as Europe's first demographic transition, when industrialization and economic growth was accompanied by rapid fertility decline. Although it is still disputed what the main courses of the decline of fertility are, it is clear that it is somewhat related to reduced benefits of children (particularly for old age security), a more conscious control of (marital) fertility, as well as to changes in the values parents attach to their off-springs (Coale 1973; Ariès 1980; Hirschman 1994). What followed was a situation where income and wealth were linked with low rather than high fertility.

The observation that wealthier persons more strongly limited their fertility called for new theoretical approaches. Researchers such as Brentano (1910: 588), Mombert (1912: 816ff.) or Mackenroth (1953: 397ff.) speculated about an inverse impact of children on social mobility. Leibenstein (1975) and Easterlin (1976) drew on concepts of a 'relative income' to explain variations in fertility. The path-breaking work in this context was, however, developed by Gary S. Becker (1960). Becker argued that parents 
do not only choose the number of children (child quantity). They also choose how much time and money they devote to each child (child quality). Becker (1993) assumes that with increasing income the demand for child quality increases disproportionately to child quantity. This produces an inverse relationship between income and fertility.

\subsection{Women in the focus of contemporary fertility theories}

Since the 1970s, the interest in fertility theory has shifted again. Dirk van de Kaa and Ron Lesthaghe have presumably become the most important proponents in fertility theory. They observe a fundamental change of values which has swept from northern to southern Europe and triggered a fertility decline known as 'Europe's second demographic transition'. Individualization, self-actualization, individual freedom and women's emancipation range prominently in their theory on fertility decline (van de Kaa 1987; Lesthaghe 1995). The labor market development or economic uncertainties are merely considered to have a short-term impact on fertility in this conceptual framework.

Economic fertility theories (in shape of the 'New Home Economics') provided a theoretical framework which puts women's employment in the focus of attention (Schultz 1974). Key assumptions of this framework are that women are chiefly responsible for childrearing and men act as providers of the household income. These things given, an increase in female employment suppresses fertility. In this framework, the increase in women's engagement in education and employment is the prime cause of the decline in fertility in developed countries (Becker 1993: 140; Butz and Ward 1979; Hotz, Klerman and Willis 1997: 298ff.).

The 1960s and 1970s mark an era where public childcare was not available yet and fathers were rarely involved in childrearing tasks. One of the most significant social changes of this time was the 'new role of women in society'. Since female emancipation and the increase in female employment coincided with a drop in fertility, it seemed only obvious to causally relate the two. The usefulness of this concept for studying the fertility development in contemporary countries has, however, been questioned recently. It has been pointed out that female employment and family life have in many countries become more compatible through public and private day care arrangements (Rindfuss et al. 1996; 
McDonald 2000). It has also been argued that fertility research has been too preoccupied by women's labor market behavior. Only little attention has been paid to the deteriorating labor market performance of the 'male breadwinner' in fertility and marriage decisions (Oppenheimer et al. 1988; Oppenheimer 2003).

\subsection{Resurgence of economic uncertainty in fertility theory}

In more recent years, researchers have (re)discovered economic uncertainty as a cause for fertility decline. Particularly Southern and Eastern Europe experienced a drastic drop in annual birth rates since the 1990s. It has been suspected that peculiarities of the Southern European labor market regimes, which culminate in high youth unemployment and precarious employment entry patterns, are related to low fertility rates in these countries (McDonald 2000: 10f.; De la Rica and Iza 2004). The labor market uncertainties that accompanied the transformation from planned to marked economies are widely regarded as a chief determinant of the fertility decline that has swept all over eastern Europe after the demise of the communist systems (Eberstadt 1994; Witte and Wagner 1995; Ranjan 1999; Kharkova and Andreev 2000). Mills and Blossfeld (2005: 1) consider growing insecurities as a major overall characteristic of modern societies which has been brought about by internationalization and globalization. These uncertainties that young adults face "seep into the partnership and parenthood domains of their lives". Youth unemployment, term-limited working contracts and unstable employment situations are thus considered to be the primary forces behind the postponement of childbearing in contemporary Europe.

The basic proposition behind this argumentation is that responsible parents will have children, when they are able to support a family. Since children are long-term commitments, it is not only the current economic situation that matters for fertility, but also expectation about the future situation. What still remains unclear in this discussion is whether these uncertainties refer to uncertainties in male employment careers, in female employment careers, or in both. While previous theoretical concepts have been preoccupied with the idea that women's career orientation is the major force behind the fertility decline, new approaches to the role of economic uncertainty stay surprisingly mute about gender roles. 


\subsection{Gender roles and economic uncertainty}

In economic theory, a standard hypothesis has been the 'male breadwinner assumption' where the woman is responsible for childrearing tasks and the man for providing the household income. In this regime, insecurities in male employment should induce couples to postpone fertility plans. Since women are expected to be care-givers, labor market developments which discourage them from engaging in an own employment career should only be beneficial for fertility developments. In that sense, insecurities in female employment careers should rather encourage parenthood.

Another more radical twist of the same argument is the work by Friedman, Hechter and Kanazawa (1994: 383ff.). They posit that specifically women with limited labor market options respond to unfavorable employment prospects by choosing the 'alternative career' of mothers. Those women are likely to perceive motherhood as a strategic choice to structure an otherwise uncertain life course. The most appealing aspect of this framework presumably is that it suggests that parenthood is a strategy to reduce life course uncertainties. What remains fairly unclear in this model is what the economic basis of such families is who opt for parenthood in times of life course insecurities. Women who consider an insecure employment situation as a suitable basis for family formation will presumably rely on partner income or on public transfers for the subsequent life course.

These considerations nevertheless suggest that there is no universal impact of uncertainty on fertility, particularly with respect to insecurities in female employment. On the one hand, women with restricted options in the labor market might accommodate themselves more readily with the role of mothers (either as single mothers or as dependent housewives). This group of women might particularly perceive precarious employment as a suitable situation to opt for parenthood. On the other hand, highly educated and career oriented educated women will more often consider economic independence as a prerequisite for family formation. They are presumably more reluctant to rely on partner income (or on public transfers) and will delay fertility decisions when they themselves are subject to an insecure labor market situation. 


\section{Empirical studies on the fertility-uncertainty nexus}

\subsection{How economic uncertainty impacts fertility}

Historical demographic literature contains numerous studies which provide evidence for a causal relationship between economic conditions and demographic behavior. For countries which followed the 'western European marriage pattern', it can be shown that economic crisis and hardships had a direct impact on nuptiality and fertility patterns (Lynch 1986; Friedlander 1992). For the post-industrialization area, there is much fewer evidence of this kind. One of the first micro-level studies which have dealt with the role of economic uncertainty in fertility is presumably the 'Indianapolis Study' (Kiser and Whelpton 1953). This study was prompted by the concern about low birth rates that followed the Great Depression in the US. However, the Indianapolis Study did not provide particularly strong evidence for the hypothesis that economic uncertainty causes low fertility rates. It might have been these discouraging results, but also the fact that many countries experienced a fertility boom during the 1950s, that caused researchers to loose interest in the relationship between low birth rates and economic uncertainty.

Since then, the favorite variable in micro-level fertility models has been women's career orientation, frequently measured by female education. Event history type models have mostly used education as a time-varying covariate, which distinguishes educational level and educational enrolment. These models generally show that educational enrolment strongly reduces first birth risks. However, after controlling for educational enrolment, no strong independent effect of educational level is usually found (Hoem 1986; Blossfeld and Huinink 1991; Kravdal 1994; Liefbroer and Corijn 1999; Kreyenfeld 2004; Lappegård and Rønsen 2004). Some more recent studies have also addressed how female unemployment or income relates to fertility. These studies only provide equivocal results (Hoem 2000; Santow and Bracher 2001; Kravdal 2002; Meron and Widmer 2002; Kieffer et al. 2005). Vikat (2004) shows that unemployment delays family formation among highly educated women in Finland. For other educational groups, unemployment fosters family formation. For Sweden, Andersson (2000) shows, for example, that a low female income delays fertility. 
Male characteristics have only rarely been considered in empirical micro-level analysis. This certainly pertains to fertility data which have mostly been collected for female respondents only. Studies which contain complete fertility histories of male respondents show that a low wage and a low educational attainment negatively influence first birth risks in Germany (Huinink 1995; Tölke and Diewald 2003). Household panels that survey the characteristics of all household members also allow for controlling for partner characteristics. The disadvantage of this data set up is that one only observes the partner's characteristics after he has moved in with the female respondent. Regarding first birth, there is every reason to believe that a selection mechanism operates at this threshold already. Males who are disadvantaged in the labor market are also disadvantaged in the partner market.

As to the role of subjective measure of economic uncertainty in fertility, only few studies exist. In order to investigate how subjective measures of economic security impacts fertility, one requires longitudinal information on both subjective indicators as well as respondent's fertility behavior. There are some cross-sectional studies which have analyzed the role of economic uncertainties for fertility intentions (Kohler and Kohler 2002; Speder and Vikat 2005). However, only few studies have addressed the role of subjective measures of economic uncertainty for real behavior. Exceptions are, for example, the studies by Witte and Wagner (1995) or by Bhaumik and Nugent (2002). Using data from the German Socio-Economic Panel, they investigate whether East German respondents who were particularly worried at unification were less likely to opt for parenthood in the subsequent years. Their investigation provides, however, only equivocal results.

\subsection{How children impact life satisfaction and economic worries}

While there exists only scarce evidence on how economic insecurity impacts fertility, there is substantial empirical research work on how marriage and fertility impacts life satisfaction. Kohler, Behrman and Skytthe (2005) use a sample of Danish twins to show that children impact well-being, accounting for unobserved heterogenity. Stutzer and Frey (2003) show with data from the German-Socio-Economic Panel how marriage 
increases subjective well-being. Holst and Trzcinski (2005) show with the same data set that the arrival of the first child increases life satisfaction.

Figure 1 shows similar results of a logistic regression model. One of the dependent variables is a binary variable for being satisfied with life. The other variable is a binary for being very worried about the personal economic situation (for the full model, see Table A1 in the Appendix). The graph shows that the arrival of the first child marks a drastic increase in life satisfaction. Life satisfaction skyrockets with the birth of the first child, hence it quickly levels off thereafter. Surprisingly, economic worries do not seem to increase significantly after childbirth.

Economic worries and life satisfaction will also range prominently in the subsequent analysis of first birth determinants. That subjective well-being is responsive to childbearing has also major implications for the study of first birth risks. It underlines that one needs to correctly take into account the temporal order between attitudes and subsequent childbearing. If one investigates how well-being impacts fertility, attitudes need to be measured clearly before pregnancy. Otherwise one will find a positive correlation between the two factors which will merely be attributed to the fact that the arrival of the first child makes people happy.

Figure 1: How the first child influences life satisfaction and economic worries

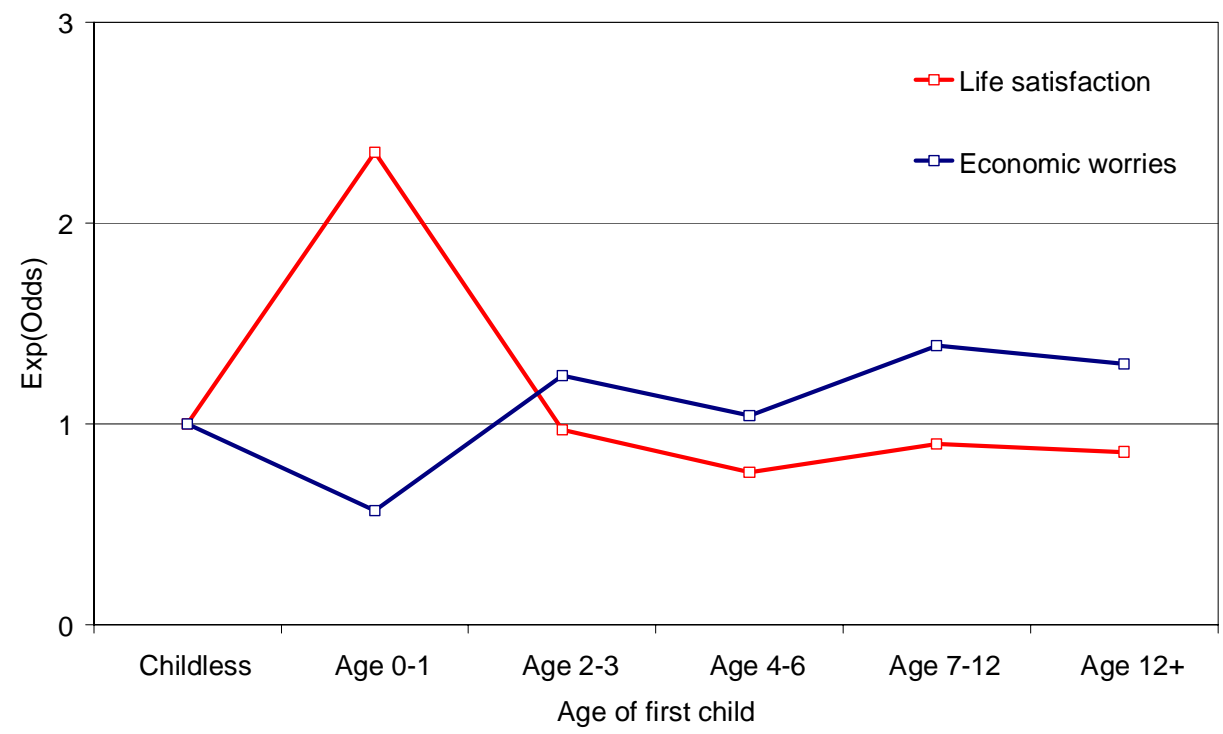

Source: Estimates from logistic regression model (see Table A1 in the Appendix for details). 


\section{Data, method and covariates}

In order to investigate how economic uncertainties impact the transition to first birth, we use data from the German Socio-Economic Panel (SOEP). The SOEP is one of the longest household panels in Europe (for details see SOEP-Group 2001). It currently provides longitudinal information for the period 1984 until 2004. The first wave of the SOEP was launched in 1984 encompassing 4,500 West German households (sample A) and an oversample of roughly 1,500 West German households with a foreign household head (sample B). Since 1984, the SOEP has been supplemented by several subsamples. For example in 1990, an 'East German sample' (sample C) has been added. In 1995, an 'immigrant sample' (sample D) was drawn. For the analysis in this study, we use respondents from the western German sample and the foreigner sample (sample A and sample B).

The SOEP is a panel study in which individuals are re-interviewed on an annual basis. It includes a battery of questions on employment, income, labor market characteristics, attitudes and household compositions. Most items are surveyed in a similar manner each year. This allows utilizing a large set of longitudinal information on a person's characteristics (see below). For fertility analysis, it is also vital to have information on the parity of a person when he or she enters the study. This information also is available from the SOEP. For sample A and B, complete fertility histories of women were surveyed. Since men's fertility histories were not recorded for members of sample A and B, we restrict the analysis to female respondents. Hence, we take into account the characteristics of the partner the woman is cohabiting with.

For some selected variables, such as source of income or activity status, the SOEP provides monthly information. For most other variables, information is surveyed for the date of interview only. In other words, the respondent is requested to give his or her current employment status or labor market position. Respondents are also requested to report if they are currently worried about their economic situation. For the time period between panel waves, we obviously do not have any information on the worries of the respondent. For simplicity, we assume that a person's characteristics which have been reported at the time of interview are fixed during the last and the following six months. 
Figure 2 visualizes this procedure. In this example, the first interview was conducted in April 1984 and the respondent reports that she is not worried when she thinks about her personal economic situation. This respondent experiences several changes in respect to her worries. In February 1988, the woman gives birth to her first child and when she is interviewed in April 1988, she is worried about her economic situation. In order to guarantee that attitudes are measured - for all cases - before pregnancy, we backdate the date of birth by twelve months. By this procedure, we make sure that we avoid reversed causation of economic uncertainty and fertility.

Figure 2: Survey design and covariates

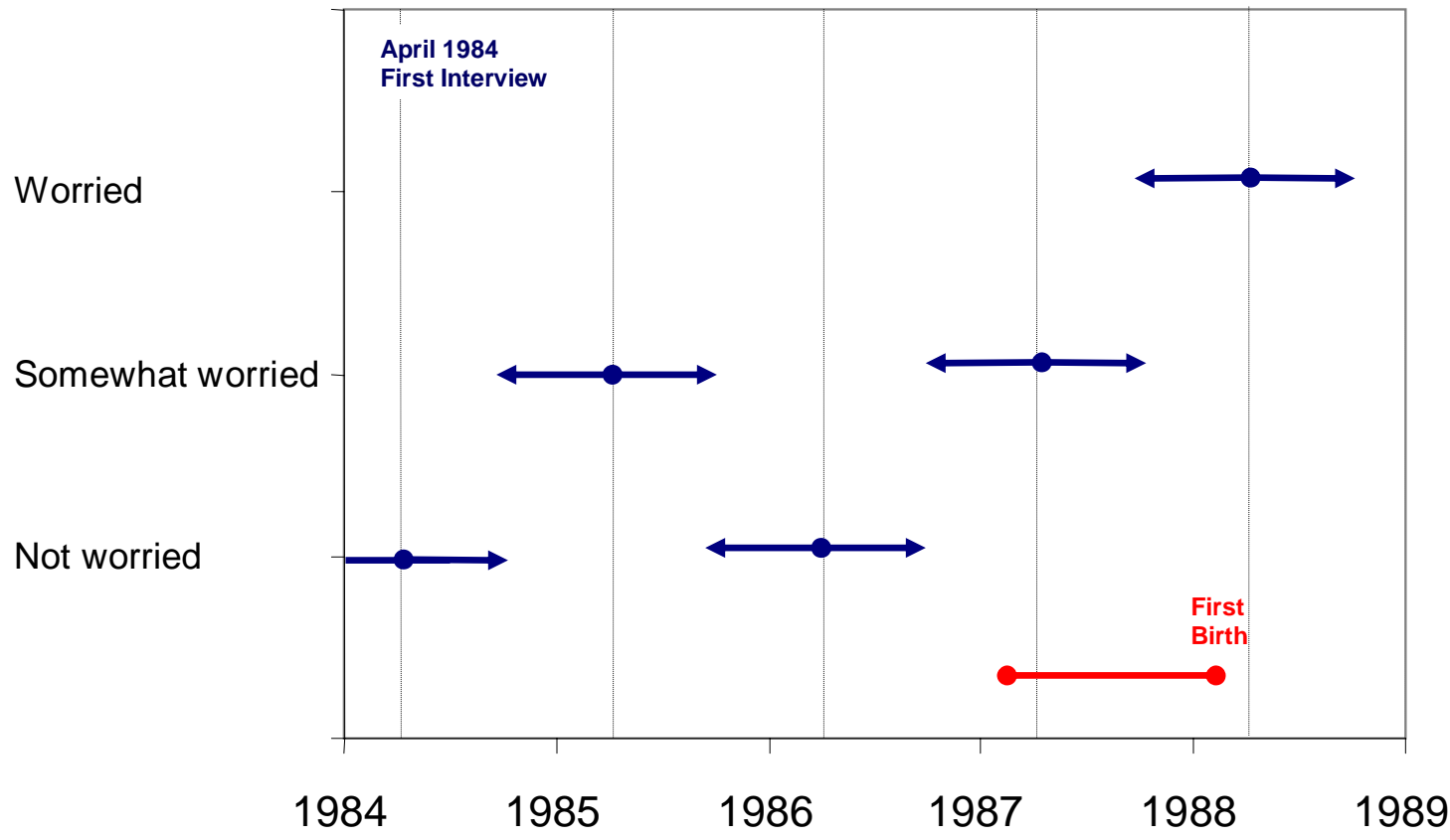




\section{Method}

We employ event history techniques to investigate how education, employment, partner characteristics and economic uncertainty impacts first birth risks. The process starts at age 18 and it ends at first pregnancy. ${ }^{1}$ Cases are censored when a person drops out of the sample or at age 45 . For the specification of the baseline hazard, we use a piecewise constant function. We restrict the multivariate analysis to the time period respondents are part of the panel study. This means that some cases are left-censored. For example, a woman who is born in 1960 is 24 year of age when she comes under observation in 1984. There are 2898 cases under observation. For these 2898 cases, we observe 963 first births. For some parts of the analysis, we only take into account periods during which the partner of the respondent lives in the same household. For this kind of analysis, we have 1547 women and 627 births at our disposal.

\section{Covariates}

One of our key interests in this study is the impact of economic uncertainty on fertility. We measure economic uncertainty by two different kinds of variables. We take into account general life satisfaction. Life satisfaction is measured on an ordinal scale in the SOEP. Respondents could choose values 0 through 10, where 0 indicates a low satisfaction with life and 10 indicates high life satisfaction. We grouped this variable into the categories low satisfaction (0-3), medium satisfaction (4-7) and high satisfaction (810). The disadvantage of life satisfaction is that it is only indirectly linked to the personal economic situation. The central variable for measuring economic uncertainty is a variable that indicates if a person reports that she is worried, somewhat worried or not worried when she thinks about her personal economic situation. This variable has several merits. It is surveyed for all respondents. Furthermore, it is among the few variables that have

1 In order to guarantee, that we avoid reversed causation, we backdate the date of birth by nine month. Therefore, we rather study first pregnancy risks than first birth risks. For improved readability, we refer to 'first birth risks' in the description of the results. 
been surveyed every year. Also it is phrased in the same way over the panel waves. ${ }^{2}$ If one looks at the percentage of women who are very worried, there is a substantial increase from 2000 to 2004. Compared to West Germans, foreigners tend to be more worried about their personal economic situations (Figure 3).

Figure 3: Percentage of women who are very worried about their personal economic situation

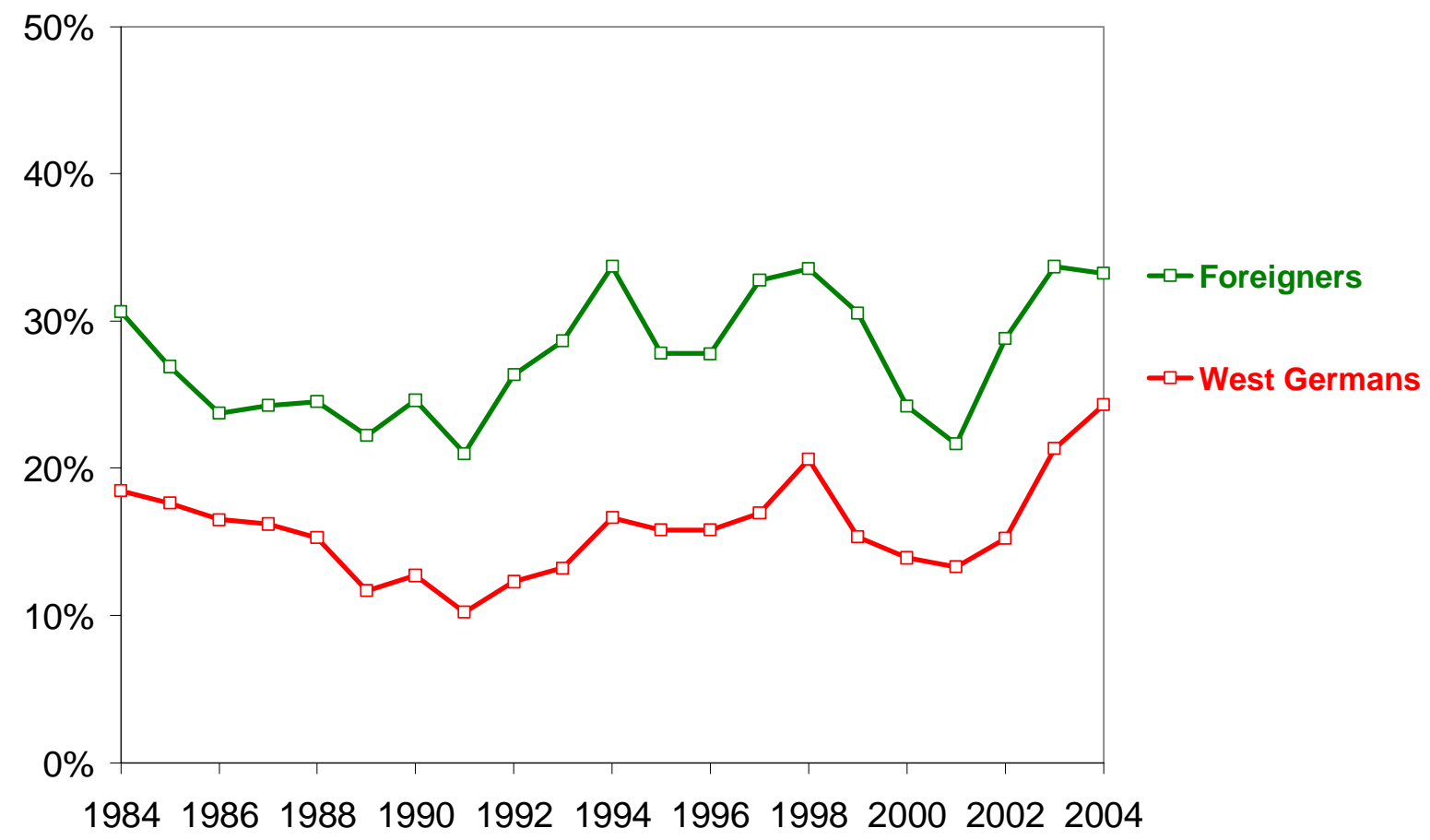

Notes: The sample comprises women aged 18-45.

Source: SOEP 1984-2004 (sample A and B)

We consider three types of 'objective measures' of economic uncertainty which are unemployment, a fixed term contract and a low income. The employment status encompasses the categories in education, employed full-time, employed part-time and

2 The exact wording of the question is as follows: 'Wie ist es mit folgenden Gebieten? Machen Sie sich da Sorgen? Um ihre eigene wirtschaftliche Situation. Große Sorgen/ einige Sorgen/ keine Sorgen.' 
unemployed. ${ }^{3}$ If a respondent reports to be employed and to attend university at the same time, we only consider the respondent's educational participation. Respondents who are employed are distinguished by whether they are holding a fixed term contract or a permanent working contract. Monthly gross wage was deflated by the price index of the German Statistical Office (Statistisches Bundesamt 2005). The base year is the year 2000. We only consider the monthly gross income of the full-time employed which we classified into the categories 0 up to 2000 Euro, 2000 Euro up to 3000 Euro, 3000 Euro up to 5000 Euro and more than 5000 Euro.

We also consider the partner's characteristics. The variables for the partner were constructed similarly to the woman's characteristics. For the male partner, educational participation also encompasses military service, though. Furthermore, we cannot distinguish between full-time and part-time employment, given the low number of males working part-time. The partner's characteristics are included only for the time period the woman is cohabiting with the partner. If the partner moves out, his characteristics are no longer considered. If a new partner moves in with the respondent, only his characteristics are taken into account.

Control variables in our model are calendar period, nationality and female education. Calendar period was grouped into the years 1984 to 1990, 1991 to 1996 and 1997 to 2003. The last date of interview is the beginning of 2004. Since we backdate the date of childbirth (and of censoring) by twelve months, the year 2004 is not covered in our analysis. Women's educational level was measured by a categorical variable that distinguishes high level ('Abitur'), medium level ('Realschulabschluss') or low level ('Hauptschulabschluss' or less). A 'Realschulabschluss' or a 'Hauptschulabschluss' is usually earned around age 16. The 'Abitur' is earned around age 18 and qualifies for university education. Even though a school degree is usually earned before age 18, we treat this variable as a time-varying covariate. This means that until respondents have finished school, they are classified as 'low level'.

3 We also grouped 'other types of non-employment' into the category of women who are unemployed. Before first pregnancy, there were rather few women who belong to this category. Omitting this category completely from the analysis did not change our results in any substantial manner. 


\section{Results}

\subsection{Insecurities in female employment careers and fertility postponement}

In the following empirical analysis, we investigate how objective and subjective measures of economic uncertainty influence first birth risks. Table 1 displays the results of a model which includes the characteristics of the female respondent. We estimate five different models which each contain a different measure of economic uncertainty. Model 1 includes the employment status. Model 2 contains a combination factor of employment status and type of work contract. Model 3 contains a combination factor of the employment status and the monthly gross wage. By 'combination factor', we mean that we combined the wage information and the employment status into a single variable. Model 4 and 5 contain the subjective indicators. We did not include all types of insecurities in a single model, because our variables partially overlap and measure similar aspects.

Let us first turn to the control variables. There is a bell-shaped impact of age on first birth risks. The hazards for family formation (or rather first pregnancy) are highest in the age bracket 25 to 28 . The age profile is pronounced, but it would be stronger if one had not controlled for the partnership status, which also relates to age. Having a partner who lives in the same household has a distinct and marked impact on first birth risks. A partner increases the transition rate to the first child by the factor 3 . Vice versa, having no partner reduces first birth risks by roughly 70 percent. Nationality has a significant impact on first birth risks, with foreigners encountering a first birth risk that is elevated by more than 30 percent. We only find a modest decline in first birth risks since the 1980s. A model that includes only age and calendar period (not presented here) shows a slightly more pronounced impact of the calendar period on first birth risks, suggesting that an increase in female education explains some of the changes in first birth rates over time. The educational level shows a negative and significant gradient. Since educational enrollment is controlled for, this result suggests that the highly educated more strongly postpone parenthood after completion of education. 
In line with other studies, we find that first birth risks are particularly low during educational participation. Compared to full-time employment, first birth risks are reduced by 60 percent when enrolled in education. Apart from this very pronounced impact of educational participation, none of the other employment variables have any substantial impact on first birth risks. Part-time employment somewhat lowers first birth risks, but this results is statistically not significant. Partially, this might be related to the low number of women working part-time before their first child is born. A similar aspect applies to the type of working contract. This variable is not significant and here also, there are fairly few respondents who are holding term-limited working contracts.

Woman's gross labor market income does not seem to impact first birth risks, either. A classical expectation on this issue would be that high female wages increase the opportunity costs of childbearing and lower the chances of a first birth for a woman. If one assumes, however, that particularly highly educated women are able to resolve the incompatibility between childrearing and employment, the situation is less clear-cut. In that case, one could argue that highly educated women postpone childbearing until they have reached a high income. In essence, wages depend on age as well as on educational attainment. The interrelation between wage, age and income is not sufficiently addressed in a model which treats education, income and age as variables that have an independent impact on first birth risks. We will come back to this issue in the subsequent analysis.

Model 4 includes the variable that indicates whether the personal economic situation is insecure, Model 5 the variable that indicates general life satisfaction. None of these indicators suggest that there is any impact of subjective measures of economic uncertainty on first birth fertility in western Germany. The quintessence of this is that neither the objective measures of economic uncertainty (fixed term contract, unemployment, a low labor market income) nor the subjective measures of economic uncertainty are related to first birth risks, neither in a positive nor in a negative manner. 
Table 1: Results from event history model, relative risks of the transition to first birth

\begin{tabular}{|c|c|c|c|c|c|}
\hline & Model 1 & Model 2 & Model 3 & Model 4 & Model 5 \\
\hline Age & & & & & \\
\hline $18-20$ & $0.81 *$ & $0.81 *$ & $0.81 *$ & $0.81 *$ & $0.81 *$ \\
\hline $21-24$ & 0.90 & 0.90 & 0.90 & 0.90 & 0.90 \\
\hline $25-28$ & 1 & 1 & 1 & 1 & 1 \\
\hline $29-32$ & $0.67 * * *$ & $0.67 * * *$ & $0.67 * * *$ & $0.67 * * *$ & $0.67 * * *$ \\
\hline $33-45$ & $0.13 * * *$ & $0.13 * * *$ & $0.13 * * *$ & $0.13 * * *$ & $0.13 * * *$ \\
\hline \multicolumn{6}{|l|}{ Calendar Period } \\
\hline $1984-1990$ & 1 & 1 & 1 & 1 & 1 \\
\hline $1991-1996$ & 0.90 & 0.91 & 0.91 & 0.91 & 0.91 \\
\hline $1997-2003$ & 0.98 & 0.99 & 0.99 & 0.99 & 0.98 \\
\hline \multicolumn{6}{|l|}{ Nationality } \\
\hline German & 1 & 1 & 1 & 1 & 1 \\
\hline Foreigner & $1.33 * * *$ & $1.33 * * *$ & $1.34 * * *$ & $1.33 * * *$ & $1.34 * * *$ \\
\hline \multicolumn{6}{|l|}{ Educational level } \\
\hline Low level & 1 & 1 & 1 & 1 & 1 \\
\hline Medium level & $0.87 *$ & $0.87 *$ & $0.87 *$ & $0.87 *$ & $0.84 *$ \\
\hline High level & $0.84 *$ & $0.84 *$ & $0.84 *$ & $0.85 *$ & $0.87 *$ \\
\hline \multicolumn{6}{|l|}{ Partnership status } \\
\hline Partner & 1 & 1 & 1 & 1 & 1 \\
\hline No (cohabiting) partner & $0.33 * * *$ & $0.34 * * *$ & $0.34 * * *$ & $0.33 * * *$ & $0.34 * * *$ \\
\hline \multicolumn{6}{|l|}{ Employment status } \\
\hline In education & $0.40 * * *$ & & & $0.40 * * *$ & $0.40 * * *$ \\
\hline Employed full-time & 1 & & & 1 & 1 \\
\hline Employed part-time & 0.77 & & & 0.77 & 0.78 \\
\hline Not employed & 1.07 & & & 1.06 & 1.08 \\
\hline \multicolumn{6}{|l|}{ Work contract } \\
\hline In education & & $0.37 * * *$ & & & \\
\hline Not employed & & 0.99 & & & \\
\hline Employed & & & & & \\
\hline -- fixed-term contract & & 1 & & & \\
\hline -- unlimited contract & & 0.88 & & & \\
\hline \multicolumn{6}{|l|}{ Monthly gross wage } \\
\hline In education & & & $0.42 * * *$ & & \\
\hline Not employed & & & 1.13 & & \\
\hline Employed part-time & & & 0.82 & & \\
\hline Employed full-time & & & & & \\
\hline -- 0-2000Euro & & & 1.06 & & \\
\hline -- 2000-3000 Euro & & & 1 & & \\
\hline -- 3000 - 5000 Euro & & & 1.04 & & \\
\hline -- more than 5000 Euro & & & 1.15 & & \\
\hline \multicolumn{6}{|l|}{ Economic worries } \\
\hline Very worried & & & & 1 & \\
\hline Somewhat worried & & & & 0.91 & \\
\hline Not worried & & & & 0.95 & \\
\hline \multicolumn{6}{|l|}{ Life satisfaction } \\
\hline Low (values 0-2) & & & & & 1 \\
\hline Medium (values 3-7) & & & & & 0.87 \\
\hline High (values 8-10) & & & & & 0.94 \\
\hline
\end{tabular}

Notes: $* * *: \mathrm{p} \leq 0.01 * *: 0.01 \leq \mathrm{p} \leq 0.05 *: 0.05 \leq \mathrm{p} \leq 0.10$. Source: SOEP 1984-2004 (own estimates) 


\subsection{The differential effect of economic uncertainty on family formation}

Following our theoretical presumptions, the impact of economic uncertainty should vary by women's career orientation. Women who can accommodate themselves with the role of housewives might not be particularly affected in their fertility plans by own labor market insecurities. Only women who consider economic independence as a prerequisite for family formation will delay parenthood, if they feel that the personal economic situation is insecure. Women with a higher education can generally expect to receive higher wages. It also seems reasonable to assume that, if female economic independence is a prerequisite for family formation, it is a matter for the highly educated. In order to address how insecurities vary by women's career orientation, we interact indicators of economic uncertainty with the woman's educational level. For the type of work contract, there were too few cases available, which is why we did not perform any interactions with this variable.

Table 2 reports an interaction of education and employment status. For this interaction, we had to group women employed part-time and full-time into one category to provide a sufficiently high sample size. There is clear-cut evidence with respect to the effect of educational participation. For all educational categories, educational enrolment lowers first birth risks significantly. Employment also has a similar impact across all educational levels. The great difference lies in the impact of unemployment. For highly educated women, first birth risks are significantly reduced if they are unemployed. Compared to employed women with a high educational level, their unemployed counterparts experience a first birth risks that is reduced by 60 percent. ${ }^{4}$ For women with a medium educational level, we do not find much of an impact of unemployment on fertility rates. For women with a low educational level, however, unemployment seems to increase the transition rate to the first child. Compared to employed women with a low educational level, first birth risks are elevated by 25 percent for their unemployed counterparts.

4 The relative risk of being unemployed for the highly educated is calculated by dividing the relative risks of unemployment (0.38) by the relative risks of employment (0.95), which equals 0.4. First birth risks are therefore lowered by 60 percent $(1-0.4) * 100)$. 
Table 2: Relative first birth risks. Model with interaction effects between female education and employment status

\begin{tabular}{|lllll|}
\hline & \multicolumn{3}{c|}{ Education } \\
& Low & Medium & High \\
\hline Employment status & & & & \\
In education & $0.45 * * *$ & $0.37 * * *$ & 0.33 & $* * *$ \\
Employed & 1 & 0.90 & 0.95 & \\
Unemployed & $1.25 *$ & 0.96 & 0.38 & $* *$ \\
\hline
\end{tabular}

Notes: Other variables in model are age, period, nationality, partnership status.

$* * *: \mathrm{p} \leq 0.01 * *: 0.01 \leq \mathrm{p} \leq 0.05 *: 0.05 \leq \mathrm{p} \leq 0.10$. Source: SOEP 1984-2004 (own estimates)

Table 3 and Table 4 provide the interaction of the subjective measures of economic uncertainty and educational level. It supports the presumption that economic worries particularly impact first birth risks among the highly educated. For women with a low educational level, the effect is rather vice versa. For example, first birth risks of women with an 'Abitur' are reduced by roughly 40 percent if they are worried about their personal economic situation (compared to being not worried). For women with a low educational level, first birth risks increase by 13 percent if they are very worried. For life satisfaction, the pattern is similar in the sense that a low life satisfaction seems only to prevent more highly educated women from having children. Low scores on life satisfaction strongly discourage highly educated women from having children. Lowly educated women with a low life satisfaction seem to be particularly amenable to the idea of parenthood.

Table 3: Relative first birth risks. Model with interaction effects between female education and economic worries

\begin{tabular}{|lrlll|}
\hline & \multicolumn{5}{c|}{ Education } \\
& Low & Medium & High & \\
\hline Economic worries & & & & \\
Very worried & 1 & 0.88 & 0.53 & $* *$ \\
Somewhat worried & 0.83 & $0.78 *$ & 0.69 & $*$ \\
Not worried & 0.88 & $0.66 * * *$ & 0.87 & \\
\hline
\end{tabular}

Notes: Other variables in model are age, period, nationality, partnership status, employment status.

$* * *: \mathrm{p} \leq 0.01 * *: 0.01 \leq \mathrm{p} \leq 0.05 *: 0.05 \leq \mathrm{p} \leq 0.10$. Source: SOEP 1984-2004 (own estimates) 
Table 4: Relative first birth risks. Model with interaction effects between female education and life satisfaction

\begin{tabular}{|lrlll|}
\hline & \multicolumn{5}{c|}{ Education } \\
& Low & Medium & High \\
\hline Life Satisfaction & 1 & $0.30 *$ & 0.31 & \\
Low (values 0-2) & 0.61 & $0.52 * *$ & 0.50 & $* *$ \\
Medium (values 3-7) & 0.64 & $0.58 *$ & 0.56 & $*$ \\
High (values 8-10) & & & \\
\hline
\end{tabular}

Notes: Other variables in model are age, period, nationality, partnership status, employment status.

$* * *: \mathrm{p} \leq 0.01 * *: 0.01 \leq \mathrm{p} \leq 0.05 *: 0.05 \leq \mathrm{p} \leq 0.10$. Source: SOEP 1984-2004 (own estimates)

Table 5 reports the interaction of education and monthly gross income. As in the previous analysis, we only consider the wages of the full-time employed. If the assumption is correct that highly educated women seek a secure economic position to have children, one would expect that low wages will defer their fertility plans. One finds rather modest support for this presumption. Women with an 'Abitur' and an income of more than 5000 Euro encounter elevated first birth risks. Since this category is rather small, it is not surprising that these results are insignificant. The income-fertility nexus is, complicated by the fact that educational level and income are closely intervened. This becomes very obvious when one considers that the combination 'low educational level' and 'income of more than 5000 Euro'. We cannot provide estimates for this combination, since there are too few cases with such characteristics.

Table 5: Relative first birth risks. Model with interaction effects between female education and monthly gross wage (of the full-time employed)

\begin{tabular}{|lccc|}
\hline & Low & $\begin{array}{c}\text { Education } \\
\text { Medium }\end{array}$ & High \\
\hline Monthly gross wage & & & \\
0-2000 Euro & 1.10 & 0.96 & 1 \\
2000-3000 Euro & 1.00 & 0.93 & 0.94 \\
3000- 5000 Euro & 0.98 & 1.00 & 0.93 \\
more than 5000 Euro & -- & 0.89 & 1.35 \\
\hline
\end{tabular}

Notes: Other variables in model are age, period, nationality, partnership status, educational participation and part-time employment

$* * *: \mathrm{p} \leq 0.01 * *: 0.01 \leq \mathrm{p} \leq 0.05 *: 0.05 \leq \mathrm{p} \leq 0.10$. Source: SOEP 1984-2004 (own estimates) 


\subsection{Insecurities in the partner's employment careers and fertility postponement}

While it might not come as a surprise that insecurities in female employment careers have an ambivalent impact on fertility, there should be less ambiguities with respect to the role of insecurities in male employment. In most countries, and in western Germany in particular, the male breadwinner model is the dominant living arrangement of families. Mother's employment rates differ by educational level, but nevertheless, women strongly reduce their employment after childbirth. Even in the year 2002, only about a quarter of West German women with children below age 3 are employed (Geisler and Kreyenfeld 2005). If they work, they rarely engage in full-time employment. Against this background, one would expect that particularly insecurities in male employment make couples postpone their fertility plans.

In order to address this issue empirically, we estimate several event history models where we control for the partner's characteristics. For this investigation, we only have the partner's characteristics for the time he is co-residing with the female respondent. This limits our analysis to the segments in women's lives when they have partners. This also means that one disregards births that occur outside of a (cohabiting) union. Since, one could assume that female and male characteristics are somewhat related, we first estimate models which only includes partner's characteristics. The last model then also includes female employment status and education.

Table 6 presents the results. Somewhat surprisingly, male educational attainment has a negative (but insignificant) impact on first birth rates. In general, one could expect that more highly educated males have high income and therefore better chances of setting up a family early in life. That we do not find this positive gradient might point to several aspects. One explanation could be that we only take into account the male's characteristics after entry into a co-residential union. Since less educated males are disadvantaged on the partner market, the analysis is selective in respect to partner characteristics. The results could also relate to educational homogamy. Men with a high 'earning potential' often live with women who have similar characteristics. Although the man might have the earning potential to support a family, the female partner's career ambition (and the incompatibility of it with childrearing) works in the opposite direction. One would be able to resolve this issue if one accounted for female characteristics. After 
controlling for female education and employment (Model 4), the coefficient for male education indeed increases slightly. However, it does not become positive, which one would expect if male earning potentials played indeed such a strong role in fertility, as it is often predicted. A very likely explanation seems to be that more highly educated men invest more in their career development during which they refrain from fatherhood. This would indicate that incompatibilities between career advancement and fertility also exist for males.

Similar to female educational participation, male educational participation suppresses the likelihood of parenthood. First birth risks are reduced by roughly 25 percent if the partner is receiving education or is doing his military service. This impact seems less strong than for female educational participation (, in the previous analysis, we showed that woman's educational participation reduces first birth risks by 60 percent). One needs to consider, though, that we only take into account periods when males are in a union. This substantially reduces the time of exposure in education for the male partner's characteristics.

Surprisingly, male employment status does not have the expected strong impact on first birth risks. Unemployment does not seem to have an impact on first birth risks at all. Only after controlling for female characteristics does male unemployment show the expected sign, in the sense that it reduces first birth risks. A similar matter applies to the impact of an unlimited working contract that has no impact on first birth risks. There is a somewhat positive impact of income on fertility. Compared to a high monthly income (3000-5000 Euro), a very high income (more than 5000 Euro) increases first birth risks by 25 percent. Apart from this pronounced impact of a very high income on fertility, the other income groups do not differ significantly. The relationship between male income and fertility is complicated by the close interrelation between age, education and income. One can, nevertheless, asses that the monthly income of the male partner does not seem to be such a powerful and straightforward predictor for first birth risks than one would expect to be the case in a 'male breadwinner regime'. 
Table 6: Results from event history model, relative risks of the transition to first birth, women with cohabiting partners

\begin{tabular}{|c|c|c|c|c|}
\hline 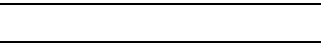 & Model 1 & Model 2 & Model 3 & Model 4 \\
\hline \multicolumn{5}{|l|}{ Age (of woman) } \\
\hline $18-20$ & 0.99 & 0.94 & 0.99 & 1.05 \\
\hline $21-24$ & 0.91 & 0.91 & 0.91 & 0.94 \\
\hline $25-28$ & 1 & 1 & 1 & 1 \\
\hline $29-32$ & $0.67 * * *$ & $0.66 * * *$ & $0.65 * * *$ & $0.64 * * *$ \\
\hline $33-45$ & $0.11 * * *$ & $0.11 * * *$ & $0.11 * * *$ & $0.11 * * *$ \\
\hline \multicolumn{5}{|l|}{ Calendar Period } \\
\hline $1984-1990$ & 1 & 1 & 1 & 1 \\
\hline 1991-1996 & 0.87 & 0.86 & 0.87 & 0.90 \\
\hline $1997-2003$ & 1.09 & 1.05 & 1.07 & 1.12 \\
\hline \multicolumn{5}{|l|}{ Nationality (of woman) } \\
\hline German & 1 & 1 & 1 & 1 \\
\hline Foreigner & $1.39 * * *$ & $1.37 * * *$ & $1.41 * *$ & $1.28 * *$ \\
\hline \multicolumn{5}{|l|}{ Partner's } \\
\hline \multicolumn{5}{|l|}{ Educational level } \\
\hline Low level & 1 & 1 & 1 & 1 \\
\hline Medium level & 0.83 & 0.83 & 0.82 & 0.85 \\
\hline High level & 0.87 & 0.86 & 0.84 & 0.92 \\
\hline \multicolumn{5}{|l|}{ Partner's } \\
\hline \multicolumn{5}{|l|}{ Employment status } \\
\hline In education & $0.76 *$ & & & \\
\hline Employed full-time & 1 & & & \\
\hline Not employed & 1.04 & & & \\
\hline \multicolumn{5}{|l|}{ Partner's } \\
\hline \multicolumn{5}{|l|}{ Work contract } \\
\hline In education & & 0.78 & & \\
\hline Not employed & & 1.06 & & \\
\hline \multicolumn{5}{|l|}{ Employed } \\
\hline -- fixed-term contract & & 1 & & \\
\hline -- unlimited contract & & 1.04 & & \\
\hline \multicolumn{5}{|l|}{ Partner's } \\
\hline \multicolumn{5}{|l|}{ Monthly gross wage } \\
\hline In education & & & 0.79 & 0.85 \\
\hline Not employed & & & 1.05 & 0.74 \\
\hline \multicolumn{5}{|l|}{ Employed } \\
\hline -- 0-2000Euro & & & 1.16 & 1.16 \\
\hline -- 2000-3000 Euro & & & 1 & 1 \\
\hline--3000 - 5000 Euro & & & 1.00 & 0.99 \\
\hline -- more than 5000 Euro & & & $1.25 *$ & 1.21 \\
\hline \multicolumn{5}{|l|}{ Woman's } \\
\hline \multicolumn{5}{|l|}{ Educational level } \\
\hline Low level & & & & 1 \\
\hline Medium level & & & & 0.96 \\
\hline High level & & & & 0.92 \\
\hline \multicolumn{5}{|l|}{ Woman's } \\
\hline \multicolumn{5}{|l|}{ Employment status } \\
\hline In education & & & & $0.57 * * *$ \\
\hline Employed full-time & & & & 1 \\
\hline Employed part-time & & & & 0.99 \\
\hline Not employed & & & & $1.41 *$ \\
\hline
\end{tabular}




\section{Conclusions}

The goal of this paper was to investigate how economic uncertainty induces fertility delay. Fertility theory has been rooted in the idea that fertility decisions require a secure economic foundation, which was usually considered to be an adequate, secure employment position of the 'male breadwinner'. Female employment was often approached via the 'opportunity cost argument' in which the labor market participation of women suppresses fertility. In this framework, women's employment and career orientation is the greatest threat to a country's reproductive level. Vice versa, low female wages, high female unemployment and bad employment chances for women should only be beneficial for high birth rates.

A standard assumption behind this thinking is that women are unable to bring in synch employment and childrearing. Women who are career oriented and emancipated stay childless in this framework. In contemporary societies, the compatibility of childrearing and employment has become somewhat more compatible due to a better access to private and public day care arrangements. Given that a family life and a working career have become more compatible, the more highly educated might not refrain from parenthood altogether. Instead they will try to accommodate the role of workers and mothers. For these women, economic independence and a secure employment situation might be particularly important for having children. It is for these women, that one would expect that labor market uncertainties have the strongest repercussions on their reproductive behavior.

The empirical results of this paper provide an ambivalent view. There is no evidence that insecurities in female employment careers generally impact first birth decisions. There are, however, interaction effects between educational level and economic uncertainties. Unemployment strongly defers fertility plans among the highly educated women. Being worried about the own personal situation has also a very profound impact on fertility behavior of those with higher educational levels. If a woman with an 'Abitur' (high level) feels worried about her personal economic situation or if she is not satisfied with her life as such, she will most likely postpone parenthood. For 
women with a 'Realschulabschluss' (medium level), the subjective feeling of economic uncertainty plays a rather insignificant role for the decision to have a first child.

It is a striking result that among the lowly educated women, economic uncertainty accelerates fertility decisions. Women with a 'Hauptschulabschluss' or without a school degree are very likely to become pregnant when they are unemployed, when they worry about their personal economic situation or when they are rather unsatisfied with their life as such. This result points to an argument developed by Friedman, Hechter and Kanazawa (1994) who posit that disadvantaged subgroups of the population choose parenthood as a strategy to structure their otherwise uncertain life course.

The empirical results of partner's characteristics gives rather weak support for the hypothesis that couples generally postpone fertility until the male breadwinner has reached a high labor market income or a secure employment situation. After controlling for female characteristics, there is a negative (but insignificant) impact of male unemployment on first birth risks. There is also a pronounced elevated fertility risk for women with partners with an income of more than 5000 Euro. However, the general results on the impact of male labor market uncertainties in the delay in fertility are less straightforward than one would expect to be the case.

\section{Acknowledgments}

I would particularly like to thank Gunnar Andersson and Cordula Zabel for valuable comments on this paper. This paper has been presented at the IUSSP-conference in Tours (France) in 2005. I also profited from various comments I got at this meeting. 


\section{References}

Adler, M.A. (1997): Social change and decline in marriage and fertility in Eastern Germany. Journal of Marriage and Family 59: 37-49.

Adsera, A. (2004): Changing fertility rates in developed countries. The impact of labor market institutions. Journal of Population Economics 17: 17-43.

Andersson, G. (2000): The impact of labour-force participation on childbearing behavior: Pro-cyclical fertility in Sweden during the 1980s and the 1990s. European Journal of Population 16: 293-333.

Ariès, P. (1980): Two successive motivations for the declining birth rate in the West. Population and Development Review 6: 645-650.

Becker, G.S. (1960): An economic analysis of fertility. Demographic and Economic Change in Developed Countries. NBER Conference Series No. 11: 209-231.

Becker, G.S. (1993): A Treatise on the Family. Enlarged edition. Cambridge, Massachusetts: First Harvard University Press.

Bhaumik, S.K./ Nugent, J.B. (2002): Does economic uncertainty have an impact on decisions to bear children? Evidence from Eastern Germany. MPIDR-Working Paper 2002-37.

Blossfeld, H.P./ Mills, M./ Klijzing, E./ Kurz, K. (eds.) (2005): Globalization, Uncertainty, and Youth in Society. New York: Routledge.

Blossfeld, H.P./ Huinink, J. (1991): Human capital investment or norms of role transition? How women's schooling and career affect the process of family formation. American Journal of Sociology 97: 143-168.

Bongaarts, J. (1999): Fertility decline in the developed world: where will it end? American Economic Review 89: 256-260.

Brentano, L. (1910): The doctrine of Malthus and the increase of population during the last decades. Economic Journal 20: 371-93

Brewster, K.L./ Rindfuss, R.R. (2000): Fertility and women's employment in industrialized nations. Annual Review of Sociology 26: 271-296.

Butz, W.P./ Ward, M.P. (1979): The emergence of countercyclical U.S. fertility. American Economic Review 69: 318-328.

Coale, A.J. (1973): The demographic transition reconsidered. International Population Conference, Liège Vol. 1: 53-72. 
De la Rica, S./ Iza, A. (2005): Career planning in Spain: Do fixed-term contracts delay marriage and parenthood? Review of Economics of the Household 3: 49-73.

Easterlin, R.A. (1976): The conflict between aspiration and resources. Population and Development Review 2: 418-425.

Eberstadt, N. (1994) Demographic shocks after communism: Eastern Germany, 1989-93. Population and Development Review 20: 137-152.

Friedlander, D. (1992): The British depression and nuptiality: 1873-1896. Journal of Interdisciplinary History 23: 19-37.

Friedman, D./ Hechter, M./ Kanazawa, S. (1994): A theory of the value of children. Demography 31: 375-104.

Geisler, E./ Kreyenfeld, M. (2005): Müttererwerbstätigkeit in Ost- und Westdeutschland. Eine Analyse mit den Mikrozensen 1991-2002. MPIDR Working Paper No. 2005033.

Gustafsson, S.S. (2001): Optimal age at motherhood: Theoretical and empirical considerations on postponement of maternity in Europe. Journal of Population Economics 14: 225-247.

Hajnal, J. (1965): European marriage patterns in perspective. In: Glass. D./ Eversley, D. (eds.): Population in History. London: 101-143.

Hirschman, C. (1994): Why fertility changes? Annual Review of Sociology 20: 203-233.

Hoem, B. (2000): Entry into motherhood in Sweden: The influence of economic factors on the rise and fall in fertility, 1986-1997. Demographic Research 2.

Hoem, J.M. (1986): The impact of education on modern family-union initiation. European Journal of Population 2: 113-133.

Holst, E./ Trzcinski, E. (2005): Hohe Lebenszufriedenheit teilzeitbeschäftigter Mütter. DIW Wochenbericht 70: 539-545.

Hotz, J.V./ Klerman, J.A./ Willis, R.J. (1997): The economics of fertility in developed countries. In: Rosenzweig, M./ Stark, O. (eds.): Handbook of Population and Family Economics. Amsterdam: 275-347

Huinink, J. (1995): Education, work, and family patterns of men: The case of West Germay. In: Blossfeld, H.P. (ed.): The New Role of Women: Family Formation in Modern Societies. Boulder (Colorado), Westview Press 247-262.

Huinink, J./ Kreyenfeld, M. (2005): Family formation in times of social and economic change: An analysis of the East German cohort 1971. In: Diewald, M. (et al.) (eds.): After the fall of the wall: Life courses in the transformation of East Germany. Palo Alto, CA: Stanford University Press (forthcoming).

Kharkova, T.L./ Andreev, E.M. (2000): Did the economic crisis cause the fertility decline 
in Russia: Evidence from the 1994 microcensus. European Journal of Population 16: 211-233.

Kieffer, A./ Marry, C./ Meron, M./ Solaz, A. (2005): The case of France. Family formation in an uncertain labor market. In: Blossfeld, H.P. (et al.) (eds.): Globalization, Uncertainty, and Youth in Society. New York, Routledge.: 105-134.

Kiser, C./ Whelpton, P.K. (1953): Resume of the Indianapolis Study of social and psychological factors affecting fertility. Population Studies 7: 95-110.

Kohler, H.P./ Kohler, I. (2002): Fertility decline in Russia in the early and mid 1990s: The role of economic uncertainty and labor market crisis. European Journal of Population 18: 233-262.

Kravdal, O. (1994): The importance of economic activity, economic potential and economic resources for the timing of first births in Norway. Population Studies 48: 249-267.

Kravdal, O. (2002): The impact of individual and aggregate unemployment and fertility in Norway. Demographic Research 6: 262-294.

Kreyenfeld, M. (2004): Fertility decisions in the FRG and GDR. Demographic Research Special Collection 3: 276-318.

Kurz, K./ Steinhage, N./ Golsch, K. (2005): Case study Germany. Global competition, uncertainty and the transition to adulthood. In: Blossfeld, H.P. (et al.) (eds.): Globalization, Uncertainty, and Youth in Society. New York, Routledge: 51-81.

Kohler, H.P./ Behrman, J. R./ Skytthe, A. (2005): Partner + children = happiness? The effects of partnerships and fertility on well-being. Population and Development Review 31: 407-445.

Lappegård, T./ Rønsen, M. (2004): The multifaceted impact of education on entry into motherhood. European Journal of Population 21: 31-49.

Leibenstein, H. (1975): The economic theory of fertility decline. Quarterly Journal of Economic 98: 1-31.

Lesthaeghe, R. (1995): The second demographic transition in western countries: An interpretation. In: Mason, K.O./ Jensen, A.M. (eds.): Gender and Family Change in Industrialized Countries. Oxford: 17-62.

Liefbroer, A./ Corijn, M. (1999): Who, what, and when? Specifying the impact of educational attainment and labour force participation on family formation. European Journal of Population 15: 45-75.

Lynch, K.A. (1986): Marriage age among French factory workers: An Alsatian example. Journal of Interdisciplinary History 16: 405-429.

Mackenroth, G. (1953) Bevölkerungslehre. Theorie, Soziologie und Statistik der Bevölkerung. Berlin: Springer. 
Marini, M.M./ Hodson, P.J. (1981): Effects of the timing of marriage and first birth of the spacing of subsequent births. Demography 18: 529-548.

Martin, S.P. (2000): Diverging fertility among U.S. women who delay child bearing past age 30. Demography 37: 523-533.

McDonald, P. (2000): Gender equity, social institutions and the future of fertility. Journal of Population Research 17: 1-16.

Meron, M./ Widmer, I. (2002): Unemployment leads women to postpone the birth of their first child. Population 57: 301-330.

Mills, M./ Blossfeld, H.P. (2005): Globalization, uncertainty and changes in early life courses. In: Blossfeld, H.P. (et al.) (eds.): Globalization, Uncertainty, and Youth in Society. New York, Routledge: 1-24.

Mombert, P. (1912): Über den Rückgang der Geburten- und Sterbeziffern in Deutschland. Archiv für Sozialwissenschaft- und Sozialpolitik 34: 794-878.

Morgan, P.S./ Rindfuss, R.R. (1999): Reexamining the link of early childbearing to marriage and subsequent fertility. Demography 36: 59-75.

Oppenheimer, V.K. (1988): A theory of marriage timing. American Journal of Sociology 94: 563-591.

Oppenheimer, V.K. (2003): Cohabiting and marriage during young men's career development. Demography 40: 127-149.

Ranjan, P. (1999): Fertility behavior under income uncertainty. European Journal of Population 15: 25-43.

Rindfuss, R. R./ Morgan, P.S./ Offutt, K. (1996): Education and the changing age pattern of American fertility: 1963-1989. Demography 33: 277-290.

Santow, G./ Bracher, M. (2001): Deferment of the first birth and fluctuating fertility in Sweden. European Journal of Population 17: 343-363.

Schultz, T.W. (ed.) (1974): Economics of the Family. Chicago, London: University of Chicago Press.

Sobotka, T. (2004): Is lowest-low fertility in Europe explained by the postponement of childbearing? Population and Development Review 30: 195-220.

SOEP-Group (2001): The German Socio-Economic Panel (GSOEP) after more than 15 years - Overview. Vierteljahreshefte zur Wirtschaftsforschung 70: 7-14.

Speder Z./ Vikat, A. (2005): Intentions to become a parent after societal transformation in Hungary. Paper presented at the IUSSP conference in Tours, France.

Statistisches Bundesamt (2005) Verbraucherpreisindizes für Deutschland. Fachserie 17, Reihe 7. Wiesbaden. 
Stutzer, A./ Frey, B.S. (2005): Does marriage make people happy, or do happy people get married? Journal of Socio-Economics (forthcoming)

Tölke, A./ Diewald, M. (2003) Berufsbiographische Unsicherheiten und der Übergang zur Elternschaft bei Männern. In: Bien, W./ Marbach, J.H. (eds.): Partnerschaft und Familiengründung. Opladen: 349-384.

Van de Kaa, Dirk J. (1987): Europe's second demographic transition. Population Bulletin 42: $1-57$.

Vikat, A. (2004): Women's labor force attachment and childbearing in Finland. Demographic Research Special collection 3: 177-212.

Witte, J.C./ Wagner, G.G. (1995): Declining fertility in East Germany after unification: A demographic response to socioeconomic change. Population and Development Review 21: 387-397. 


\section{Appendix}

Table A1: Results from logistic regression model on life satisfaction and economic worries

\begin{tabular}{|c|c|c|c|c|}
\hline & \multicolumn{2}{|c|}{ High Life Satisfaction } & \multicolumn{2}{|c|}{ Economic Worries } \\
\hline & Model 1a & Model 1b & Model 2a & $2 a$ \\
\hline \multicolumn{5}{|l|}{ Age of first child } \\
\hline Childless & 1 & 1 & 1 & 1 \\
\hline Age $0-1$ & $2.35 * *$ & $2.43 * *$ & 0.57 & 0.49 \\
\hline Age 2-3 & 0.97 & 1.07 & 1.24 & 0.96 \\
\hline Age 4-6 & 0.76 & 0.81 & 1.04 & 0.89 \\
\hline Age 7-12 & 0.90 & 0.99 & 1.39 & 1.11 \\
\hline Age $12+$ & 0.86 & 0.95 & $1.30 *$ & 1.00 \\
\hline \multicolumn{5}{|l|}{ Age of respondent } \\
\hline Age $18-25$ & $1.55 * * *$ & $1.55 * * *$ & 0.89 & 0.87 \\
\hline Age $26-35$ & 1 & 1 & 1 & 1 \\
\hline Age $36-45$ & 0.88 & 0.88 & 1.02 & 1.04 \\
\hline Age $46-55$ & 0.83 & $0.77 *$ & 0.86 & 1.01 \\
\hline Age 56-65 & 0.98 & 0.91 & $0.50 * * *$ & $0.59 * * *$ \\
\hline Age $65+$ & 1.06 & 0.98 & $0.45 * *$ & $0.52 * * *$ \\
\hline \multicolumn{5}{|l|}{ Nationality } \\
\hline Foreigner & 1 & 1 & 1 & 1 \\
\hline German & 1.22 & 1.10 & $0.67 * *$ & 0.88 \\
\hline \multicolumn{5}{|l|}{ Region } \\
\hline East Germany & $0.59 * * *$ & $0.64 * * *$ & $1.73 * * *$ & $1.42 * * *$ \\
\hline West Germany & 1 & 1 & 1 & 1 \\
\hline \multicolumn{5}{|l|}{ Family status } \\
\hline Married & 1 & 1 & 1 & 1 \\
\hline Divorced, separated, widowed & $0.71 * * *$ & $0.77 * * *$ & $1.69 * * *$ & $1.34 * * *$ \\
\hline Single & $0.62 * * *$ & $0.69 * * *$ & $1.42 * *$ & 1.09 \\
\hline \multicolumn{5}{|l|}{ Employment status } \\
\hline In education & 1.01 & 0.88 & 0.82 & 1.20 \\
\hline Employed full-time & 1 & 1 & 1 & 1 \\
\hline Employed part-time & 1.01 & 0.92 & 0.79 & 1.01 \\
\hline Not employed & 0.96 & 0.93 & 0.83 & 0.92 \\
\hline Registered unemployed & $0.32 * * *$ & $0.34 * * *$ & $3.83 * * *$ & $3.49 * * *$ \\
\hline \multicolumn{5}{|l|}{ Education } \\
\hline No degree & $0.80 * *$ & 0.85 & 1.19 & 1.04 \\
\hline Vocational degree & 1 & 1 & 1 & 1 \\
\hline University degree & $1.53 * * *$ & $1.34 * *$ & $0.62 * * *$ & 0.83 \\
\hline \multicolumn{5}{|l|}{ Equivalent household income } \\
\hline 0-1000 Euro & & 1 & & 1 \\
\hline 1000-1500 Euro & & $1.27 * *$ & & $0.49 * * *$ \\
\hline 1500-2000 Euro & & $1.65 * * *$ & & $0.29 * * *$ \\
\hline More than 2000 Euro & & $2.01 * * *$ & & $0.15 * * *$ \\
\hline Number of cases & 4035 & 4035 & 4029 & 4029 \\
\hline Percentage satisfied/ worried & $44.0 \%$ & $44.0 \%$ & $24.9 \%$ & $24.9 \%$ \\
\hline
\end{tabular}

Notes: The sample comprises women aged 18 and older. The dependent variable in Model 1a is a binary variable for 'high life satisfaction'. Life satisfaction was measured on a scale which ranks from the values 0 to 10 . 'High life satisfaction' refers to the values 8 through 10 . The reference category includes the values 0 through 7 . The dependent variable in Model $1 \mathrm{~b}$ is a binary variable for being very worried about the economic situation. The reference category is being somewhat worried or being not worried.

$* * *: \mathrm{p} \leq 0.01 * *: 0.01 \leq \mathrm{p} \leq 0.05 *: 0.05 \leq \mathrm{p} \leq 0.10$. Source: SOEP 2004, sample F (own estimates) 